\title{
Evaluation of Leprosy Control Programmes: Some Suggestions for Operational and Epidemiological Assessments ${ }^{*}$
}

\author{
L. M. BECHELLI and V. MARTINEZ DOMINGUEZ \\ Leprosy, Division of Communicable Diseases, World Health Organization, \\ Geneva, Switzerland
}

With existing agents and methods, the object of leprosy control projects is to reduce progressively over a period of many years the morbidity of leprosy to a level at which it no longer presents an important public health problem. The achievement of this objective depends on several measures, administrative, medical, social and legal, and on health education and training of personnel.

The assessment of a leprosy project should therefore be concerned with all the measures applied in the control of the disease. In this note we shall deal only with the medical measures. Moreover, to limit the length of the paper, we shall suggest only the assessment measurements without considering the interpretation of results which may derive from the evaluation: also we shall not discuss the actions or measures which could be pertinent after the assessment. We shall stress that in the interpretation of results, in the choice of the best strategy to reach the objectives, and in the action to be taken after evaluation, all the local factors should be taken into account.

The evaluation of the medical measures should be concerned with the operational aspects of the project (operational assessment) and with the trend of the disease under the influence of the control measures, of ten associated with other factors (epidemiological assessment).

For both types of assessment it is indispensable to have the relevant base-line information, and for the former it is necessary to know whether or not the programme has quantitatively defined objectives and also to know the priorities adopted. In each country or area the measurement indicators to be selected, and the interpretation of the findings, should be considered in the light of these elements. In fact, to consider only one of these factors, in control programmes with quantitatively defined objectives, the assessment at central level or in each unit is more easily done by comparing the achievement in each activity (cases to be diagnosed, treated, etc.) with the target proposed for monthly, quarterly or annual periods.

\footnotetext{
* Prepared for a meeting on Assessment Measurements of Leprosy Control, convened by the Indian Council of Medical Research, 28 July-1 August, 1969.

$\dagger$ Reprinted from Bull. Wld Hlth Org. (1970) 42, 631-634 by kind permission of Chief, Technical Publications, WHO.
} 
It should be stressed that this report is intended to give general guidance on operational and epidemiological assessments applicable on a global basis but useful for adaptation to the actual situation existing in any given country. A few countries, with good recording systems, would be able to utilize the indicators suggested, while at the other extreme there are countries in which only a certain number of these indicators could be selected. Each country should, in fact, choose appropriate indicators.

\section{Base-line Information for Evaluation}

For evaluation purposes it is essential to have information* on:

(1) Characteristics of the area, including geographical, climatic, socio-economic and cultural conditions, communications, etc.

(2) The population, age and sex composition and rural/urban distribution.

(3) Health situation and health services structure.

(4) Leprosy service structure, technical policy, priorities.

(5) Characteristics of leprosy endemics, known prevalence, number of registered cases and their classification, age and sex distribution in the rural and urban areas before the start of the project. Prevalence should have been estimated; if not it should be estimated in order to establish targets.

The most reliable method of estimating prevalence is by a random sampling survey. However, as this is very expensive, the prevalence is generally estimated by taking into account information readily available in the area concerning known cases and the proportion of lepromatous (L) + borderline (B), indeterminate (I) and tuberculoid $(\mathrm{T})$ cases. With this information the specific prevalence rates (sex, age, each form of leprosy) should also be estimated. Bechelli and Martínez Domínguez (1966) made a proposal for the estimation of prevalence taking into account the findings of the WHO Leprosy Epidemiological Team. Estimates should be adjusted in the course of the campaign, taking into account the data collected.

(6) Resources: (a) budget for health and leprosy service (for in-patients and for out-patients); (b) health services in the area and co-operation in leprosy control; (c) leprosy service personnel and their training: number of doctors (full-time and part-time); $\dagger$ number and kind of paramedical personnel; number of social workers; administrative personnel; others (drivers, porters, etc.); (d) facilities for medical assistance to leprosy patients-number and capacity of sanatoria and/or facilities for temporary hospitalization; dispensaries, skin clinics, treatment centres, mobile units, etc., and their location; laboratory facilities; (e) training facilities; (f) transport facilities; (g) equipment; (h) other possible resources (number of practitioners working in the area, voluntary agencies and their activities).

\section{Operational Assessment}

When assessing the operational aspects of a project the first thing to establish is

* Details are given of information which can be useful for programming and evaluating leprosy control projects in: Bechelli, L. M. (1966) A Guide to Leprosy Control (unpublished document available, on request, from Leprosy, World Health Organization, Geneva, Switzerland).

$\dagger$ Estimated workload for each category of personnel. 
whether the programme includes quantitatively defined objectives. If there are quantitative objectives, at central or at unit level, it is easy to assess the development of the programme by comparing the estimates at the beginning of the year for each activity with their accumulated monthly projections.

In countries where the leprosy projects do not have annual targets, the evaluation can be undertaken by using several measurement indicators. These can also be considered for the first group of countries, to complement the assessment of targets.

In the light of the above, every project should have quantitatively defined objectives, as stressed initially by the Pan American Sanitary Bureau/WHO Regional Office for the Americas (1963) at the Leprosy Seminar held at Cuernavaca and in unpublished papers prepared for that seminar by R. Huerta and F. Pereda and later again by the WHO Expert Committee on Leprosy (1966). Guide-lines for establishing yearly timetables are given in these papers and documents.

Timetables should be prepared taking into account the resources, targets and priorities adopted in the programmes (treatment and follow-up examination of L + B cases, surveillance of their contacts, and treatment of indeterminate cases).

For an assessment it is also essential to know whether the control project has adopted a system of priorities and if a target has been fixed for the proportion of $\mathrm{L}+\mathrm{B}$ cases to be detected and treated in a certain period of time.

The priorities recommended by the WHO Expert Committee on Leprosy (1966) are as follows: "Countries with limited budgets, only a few physicians, and facing other serious problems, should treat first of all the lepromatous and other infectious cases and the indeterminate lepromin negative. They should keep child household contacts, especially of infectious cases, under surveillance and try to help patients in the prevention of disabilities. Means and personnel should be concentrated on the infectious cases and their contacts, particularly children.

"At the other extreme, countries with adequate budgets and good leprosy services, whether or not integrated in the public health services, should diagnose and treat as early as possible all patients, maintain surveillance of all contacts, prevent disabilities, rehabilitate all patients with deformities, and examine certain population groups, in particular, children."

Several measurement indicators can be suggested:* they will enable an operational assessment to be made of certain activities. In listing these indicators we have adopted the classification of leprosy recommended by the WHO Expert Committee on Leprosy (1966).

\section{CASE-FINDING}

(a) Contact tracing (annual examination):

(i) proportion of contacts examined yearly; (ii) proportion of contacts of $\mathrm{L}+\mathrm{B}$ cases examined yearly. The same for contacts of I and $\mathrm{T}$ cases.

(b) Proportion of cases among persons referred or reported by physicians and others as possible patients, and proportion of $\mathrm{L}+\mathrm{B}$, I and $\mathrm{T}$ cases detected.

(c) Proportion of cases among persons who spontaneously requested examination, and proportion of $\mathrm{L}+\mathrm{B}, \mathrm{I}$ and $\mathrm{T}$ cases detected.

\footnotetext{
* The numbers used as numerators and denominators for obtaining the proportions and/or rates are also of interest for appraising the development of the projects.
} 
(d) Proportion of leprosy cases in skin clinics and proportion of $\mathrm{L}+\mathrm{B}$, I and $\mathrm{T}$ cases detected.

(e) Proportion of leprosy cases in school surveys and proportion of $\mathrm{L}+\mathrm{B}, \mathrm{I}$ and $T$ cases detected.

(f) Proportion of leprosy cases detected in the examination of recruits, workers and others, and proportion of $\mathrm{L}+\mathrm{B}, \mathrm{I}$ and $\mathrm{T}$ cases detected.

(g) Proportion of leprosy cases in mass surveys, and proportion of L + B, I and $\mathrm{T}$ cases detected.

(h) Proportion of registered cases in relation to the estimated total number of cases. (No. of $\mathrm{L}+\mathrm{B}$ cases detected up to .../no. of estimated cases at the end of this period) $\times 100$.

(i) Proportion of cases wrongly diagnosed.

(j) Proportion of cases incorrectly classified.

TREATMENT

(a) No. of patients under treatment in the year/no. of patients requiring treatment in the year* $\times 100$.

(b) No. of patients of $\mathrm{L}+\mathrm{B}$ under treatment in the year/no. of patients of $\mathrm{L}+\mathrm{B}$ requiring treatment. The same for I and for $\mathrm{T}$ patients.

In (a) and (b), consider if treatment is regular (patient conforming to at least $75 \%$ of the recommended number of attendances $\dagger$ ) or irregular (less than $25 \%, 25$ to $50 \%$ and 51 to $74 \%$ ).

\section{INACTIVITY $\ddagger$}

(a) Percentage of inactive leprosy cases in relation to the total no. of cases (related to regular and irregular treatment).

(b) Percentage of $\mathrm{L}+\mathrm{B}$ inactive cases (related to regular and irregular treatment), if possible by cohorts. The same for I and T cases.

\section{REACTIVATION $\S$}

(a) Proportion of reactivations related to treatment (regular or irregular).

(b) Proportion of reactivation of $\mathrm{L}+\mathrm{B}$ patients. The same for I and $\mathrm{T}$ patients.

\section{CASES RELEASED FROM CONTROL}

(a) Proportion of patients released from control related:

(i) to total no. of patients under treatment; (ii) to total no. of inactive cases.

Study of cohorts is preferable.

(b) Proportion of $\mathrm{L}+\mathrm{B}$ related:

(i) to total no. of $\mathrm{L}+\mathrm{B}$ patients under treatment; (ii) to total no. of $\mathrm{L}+\mathrm{B}$ inactive cases.

The same for I and T cases.

* Number of patients registered excluding those released from control, dead or emigrated.

$\dagger$ Regular treatment is defined as follows: "A patient conforming to at least $75 \%$ of the recommended number of attendances should be considered to be attending regularly" (WHO Expert Committee on Leprosy, 1960).

† A leprosy patient without any sign of clinical activity and with negative bacteriological examination should be considered as an "inactive case" (WHO Expert Committee on Leprosy, 1966).

$\S$ When an inactive case again presents active lesions and/or bacterial positivity. 


\section{RELAPSE* (OF CASES RELEASED FROM CONTROL)}

(a) Proportion of cases relapsed related to the total no. of patients released from control.

(b) Proportion of relapsed $\mathrm{L}+\mathrm{B}$ related to the total no. of $\mathrm{L}+\mathrm{B}$ patients released from control. The same for I and for $\mathrm{T}$ patients.

\section{SULFONURIA TEST}

(a) Proportion of leprosy patients with positive sulfonuria test in relation to total no. of patients supposed to be under treatment.

(b) Proportion of $\mathrm{L}+\mathrm{B}$ patients with positive test in relation to the no. of $\mathrm{L}+\mathrm{B}$ patients supposed to be under treatment. The same for I and for $\mathrm{T}$ patients.

\section{FOLLOW-UP EXAMINATIONS (AT LEAST ONCE A YEAR)}

(a) Proportion of patients examined yearly (or every 6 months) related to the no. of patients requiring treatment.

(b) Proportion of $\mathrm{L}+\mathrm{B}$ patients examined yearly (or every 6 months) related to the no. of $\mathrm{L}+\mathrm{B}$ patients under treatment. The same for I and for $\mathrm{T}$ patients.

OUT-OF-CONTROL CASES $\dagger$

(a) Proportion of leprosy patients out of control (related to the total no. of patients requiring surveillance).

(b) Proportion of $\mathrm{L}+\mathrm{B}$ patients out of control (related to the no. of $\mathrm{L}+\mathrm{B}$ patients requiring surveillance). The same for I and for $\mathrm{T}$ patients.

\section{ANNUAL PROPORTION OF DISABILITIES IN NEWLY REGISTERED PATIENTS (RELATED TO EACH FORM OF LEPROSY)}

\section{RATIO OUT-PATIENTS/IN-PATIENTS AND THE RATIO OF THE COST PER PATIENT YEAR IN-PATIENT/OUT-PATIENT}

Cost analysis concerning in-patient and out-patient care is therefore needed, if possible with regard to the main activities.

\section{Epidemiological Assessment}

It is known that the best possible indicator for an epidemiological assessment is the annual incidence rate. However, reliable rates can be obtained only in research projects with an excellent coverage of the population surveyed; in leprosy control projects it is very difficult to get reliable figures for incidence.

For this reason, the annual rate of newly registered cases and their classification are mainly used to evaluate the epidemiological trend. Because of the limitations of antileprosy drugs and of the lack of a vaccine to prevent the disease (the studies on BCG are still in progress), it is not possible to expect a considerable reduction of this rate after a few years of control work. Consequently one has to multiply the indicators to be able to recognize any epidemiological improvement.

\footnotetext{
* Once inactivity is achieved, full treatment should be continued for different periods of time before the patient is released from control. These periods should be $1 \frac{1 / 2}{2}$ years for tuberculoid, 3 years for indeterminate and 5 years for lepromatous and borderline cases.

+ When a case released from control again presents active lesions and/or bacterial positivity.
} 
These indicators should be appraised in connexion with some of those used for operational assessment: in fact, some of them may be used for both the operational and the epidemiological assessments.

Furthermore, good epidemiological achievements reflect, to a variable extent, the success of the operational measures. While we should have an evaluation of the operational measures in short periods (every 3 or 6 months or even monthly) the epidemiological assessment should be made after long periods, preferably after 5,10 and more years.

The following indicators-related to age (mainly below 15) and sex when pertinent-are suggested for the epidemiological assessment:

(1) Annual incidence rates or annual rates of newly registered cases.

(2) Forms of leprosy of annually and newly registered cases (proportion and rate).

(3) Items (1) and (2) related to selected groups of population (contacts, schoolchildren, soldiers, etc.): (a) attack rate among contacts examined yearly; (b) attack rate among contacts of $\mathrm{L}+\mathrm{B}$ patients examined yearly. The same for contacts of I and T patients; (c) proportion of newly registered contacts examined yearly and attack rate; (d) proportion of newly registered contacts of $L+B$ patients examined yearly and attack rate. The same for contacts of $\mathrm{I}$ and $\mathrm{T}$ patients; (e) proportion of $\mathrm{L}+\mathrm{B}$, I and $\mathrm{T}$ cases detected in (a), (b) and (d); (f) attack rates and proportion of $\mathrm{L}+\mathrm{B}, \mathrm{I}$ and $\mathrm{T}$ cases detected in cohorts of contacts of $\mathrm{L}+\mathrm{B}$, of I and $\mathrm{T}$ patients.

(4) Prevalence rate.

(5) Prevalence rates in selected groups of population (contacts, schoolchildren, soldiers, etc.).

(6) Proportion of bacteriologically negative cases among $\mathrm{L}+\mathrm{B}$ patients under treatment (by cohorts).

(7) Proportion of L and B, I and T cases rendered inactive* (by cohorts).

(8) Reactivation (already considered under operational assessment).

(9) Proportion of cases released from control $\dagger$ related to (a) patients under treatment and (b) patients under treatment + out-of-control cases.

(10) Proportion of relapses related to each form of leprosy, mainly $\mathrm{L}+\mathrm{B}$ cases.

\section{References}

Bechelli, L. M. and Martínez Domínguez, V. (1966). Bull. Wld Hlth Org. 34, 811-826.

Pan American Sanitary Bureau/WHO Regional Office for the Americas (1963). Seminario sobre lepra: documentos de trabajo, conclusiones y recomendaciones, Cuernavaca, Mexico, 1963, Washington (Publicaciones cientificas No. 85).

WHO Expert Committee on Leprosy (1960). Wld Hlth Org. techn. Rep. Ser., No. 189.

WHO Expert Committee on Leprosy (1966). Wld Hlth Org. techn. Rep. Ser., No. 319.

\footnotetext{
* "Out of control", "absentee", "lost sight of" and other terms have been used for registered patients who have not been under control for 2 or more years (WHO Expert Committee on Leprosy, 1966).

$\uparrow$ Criteria for inactivity and release from control should be given.
} 